\title{
Photocatalytic Degradation of 2,6-Dichlorophenol in Aqueous Phase Using Titania as a Photocatalyst
}

\author{
Sushil Kumar Kansal*, Mani Chopra \\ University Institute of Chemical Engineering \& Technology, Panjab University, Chandigarh, India \\ Email: *sushilkk1@yahoo.co.in, sushilkk1@pu.ac.in
}

Received June 4, 2012; revised July 5, 2012; accepted July 18, 2012

\begin{abstract}
The paper includes the studies on photocatalytic degradation of 2,6-DCP in aqueous phase using titania (PC-105) as a photocatalyst. The degradation experiments were carried out by irradiating the aqueous suspensions of the model compound in the presence of photocatalysts under UV light. The rate of degradation was estimated from residual concentration spectrophotometrically. Various parameters affecting the degradation process viz. catalyst dose, $\mathrm{pH}$, initial substrate concentration and time were investigated in order to obtain their optimum values. The maximum degradation of 2,6-DCP was achieved with $1.25 \mathrm{~g} / \mathrm{L}$ catalyst dose at $\mathrm{pH}-4$. The disappearance of 2,6-DCP obeyed pseudo-first order kinetics and the rate constant value was calculated to be $4.78 \times 10^{-4} \cdot \mathrm{s}^{-1}$.
\end{abstract}

Keywords: Photocatalysis; Dichlorophenol; Titania; UV Light; Degradation

\section{Introduction}

Chlorophenols (CPs) constitute a particular group of priority toxic pollutants listed by the US EPA in the Clean Water Act [1-3] and by the European Decision 2455/ 2001/EC [4]. These pollutants are highly toxic and hardly biodegradable [5]. They are being introduced continuously into the aquatic environment as a result of several anthropogenic activities. CPs may be also generated as by-products during waste incineration, the bleaching of pulp with chlorine, and in the dechlorination of drinking water [6-9]. The variety, toxicity and persistence of CPs can directly present a threat to humans through contamination of drinking water supplies e.g. surface and ground water. They may produce disagreeable taste and odor to drinking water at concentrations below $0.1 \mu \mathrm{g} / \mathrm{L}$ [10] and adverse effects on the environment [11]. These contaminants are a major health concern because of their extremely high endocrine disrupting potency and genotoxicity. Consequently, considerable efforts have been devoted to develop a suitable purification method that can easily destroy these bio-recalcitrant contaminants. In recent years, the heterogeneous photocatalytic oxidation process employing $\mathrm{TiO}_{2}$ and UV light has emerged as a promising method for the degradation of persistent organic pollutants and produces more biologically degradeable and less toxic substances $[12,13]$. This process is largely dependent upon the in-situ generation of hydroxyl radicals under ambient conditions which are capable of

\footnotetext{
"Corresponding author.
}

converting a wide spectrum of toxic organic compounds including the non-biodegradable ones into relatively innocuous end products such as $\mathrm{CO}_{2}$ and $\mathrm{H}_{2} \mathrm{O}$. Ku and Hsieh [14] observed almost complete degradation of 2,4-dichlorophenol in aqueous solution under UV light in few hours of irradiation time and it was found that the degradation rate was influenced by the catalyst loading and $\mathrm{pH}$ of the solution. Bandara et al. [15] investigated the photocatalytic degradation of mono, di and trichlorophenols with $\mathrm{TiO}_{2}$ and iron oxide aqueous suspensions and reported that the complete mineralization of chlorophenols was seen with $\mathrm{TiO}_{2}$ whereas with iron oxide, only partial mineralization was observed. Antonaraki et al. [16] studied the photocatalytic degradation of all chlorophenols in the presence of $\mathrm{H}_{2} \mathrm{O}_{2}$ or polyoxometallate (POM) photocatalyst $\mathrm{PW}_{12} \mathrm{O}_{40}^{3-}$ under UV and visible light in aqueous phase. Saritha et al. [17] studied the degradation of 4-chloro-2-nitrophenol using different AOPs (UV, $\mathrm{H}_{2} \mathrm{O}_{2}, \mathrm{UV} / \mathrm{H}_{2} \mathrm{O}_{2}$, Fenton, UV/Fenton and $\mathrm{UV} / \mathrm{TiO}_{2}$ ). The different parameters like $\mathrm{pH}$, peroxide concentration, iron concentration and $\mathrm{TiO}_{2}$ loading were varied to assess their effect on degradation. The degradation was estimated using COD reduction and compound reduction using spectrophotometeric methods which was further validated with HPLC studies. The order of degradation was: $\mathrm{UV} /$ Fenton $>\mathrm{UV} /$ Titania $>\mathrm{UV} / \mathrm{H}_{2} \mathrm{O}_{2}>$ Fenton $>\mathrm{H}_{2} \mathrm{O}_{2}>$ UV. Information from various investigations suggests that the photocatalytic degradation of phenol and its chloro derivatives is mainly dependent upon the solution $\mathrm{pH}$, catalyst type and dose, substrate 
type and concentration, light intensity etc. Therefore understanding the impacts of various parameters on the photocatalytic degradation efficiency is of paramount importance when choosing a sustainable, efficient technique for wastewater treatment.

Various reports have been reported dealing with the photodegradation of phenol and its chloro derivatives by employing metal oxide photocatalysts but only a few studies have been conducted for the degradation of 2,6DCP. Therefore this paper aims to study the photo-catalytic degradation of 2,6-DCP using $\mathrm{TiO}_{2}$ as a photo-catalyst. Further optimization of different process parameters has been carried out.

\section{Experimental}

\subsection{Materials}

Titanium PC-105 was gifted by Millennium Inorganic Chemicals, France and was used as received. 2,6-DCP was obtained from CDH chemicals. Double distilled water was used for preparation of various solutions. $1 \mathrm{M}$ $\mathrm{HCI}$ or $1 \mathrm{M} \mathrm{NaOH}$ was used to adjust the desired $\mathrm{pH}$.

\subsection{Photocatalytic Reactor}

The photochemical degradation experiments were performed in a batch reactor whose detail is given elsewhere [18]. The temperature was maintained constant throughout the reaction time. The spectra were taken with UVvis spectrophotometer (Shimadzu UV-2450 PC).

\subsection{Procedure}

A fixed amount of photocatalyst $\mathrm{TiO}_{2}$ was added to 1000 $\mathrm{mL}$ of $25 \mathrm{mg} / \mathrm{L}$ solution of 2,6-DCP in each trial at defi- nite $\mathrm{pH}$. The suspension was subjected to irradiation under UV light for a fixed interval of time. The aqueous suspension was externally circulated through the reactor with the help of a pump. An aliquot was taken out at fixed time intervals and filtered through a Millipore syringe filter of $0.45 \mu \mathrm{m}$.

Absorption spectra were recorded at $\lambda_{\max }=283 \mathrm{~nm}$. The rate of degradation was studied in terms of changes in absorption spectra at maximum wavelength. The percentage degradation was calculated as follows:

$\%$ Degradation $=100 \times\left(\mathrm{C}_{0}-\mathrm{C}\right) / \mathrm{C}_{0}$, where $\mathrm{C}_{0}=$ initial concentration of 2,6-DCP, C = concentration of compound after photoirradiation.

\section{Results and Discussion}

\subsection{Photolysis/Photocatalytic Degradation of 2,6-DCP}

The photocatalytic degradation of 2,6-DCP was investigated under three different experimental conditions: 1) UV alone 2) Dark $\left.+\mathrm{TiO}_{2} 3\right) \mathrm{UV}+\mathrm{TiO}_{2}$. The concentration of 2,6-DCP in each solution was $25 \mathrm{mg} / \mathrm{L}$. The results are given in Figure 1. 10\% removal was achieved due to adsorption on $\mathrm{TiO}_{2}$ as shown in figure and only $14 \%$ degradation was achieved when suspension was irradiated under UV light in the absence of $\mathrm{TiO}_{2}$. However degradation under $\mathrm{UV}+\mathrm{TiO}_{2}$ was seen to be $52 \%$ after 30 minutes of irradiation.

\subsection{Optimization of Process Parameters for the Photocatalytic Degradation of 2,6-DCP}

To optimize the values of different operational parameters affecting the degradation, experiments were conducted by varying the catalyst dose $\left(\mathrm{PC}-105 \mathrm{TiO}_{2}\right)$ from

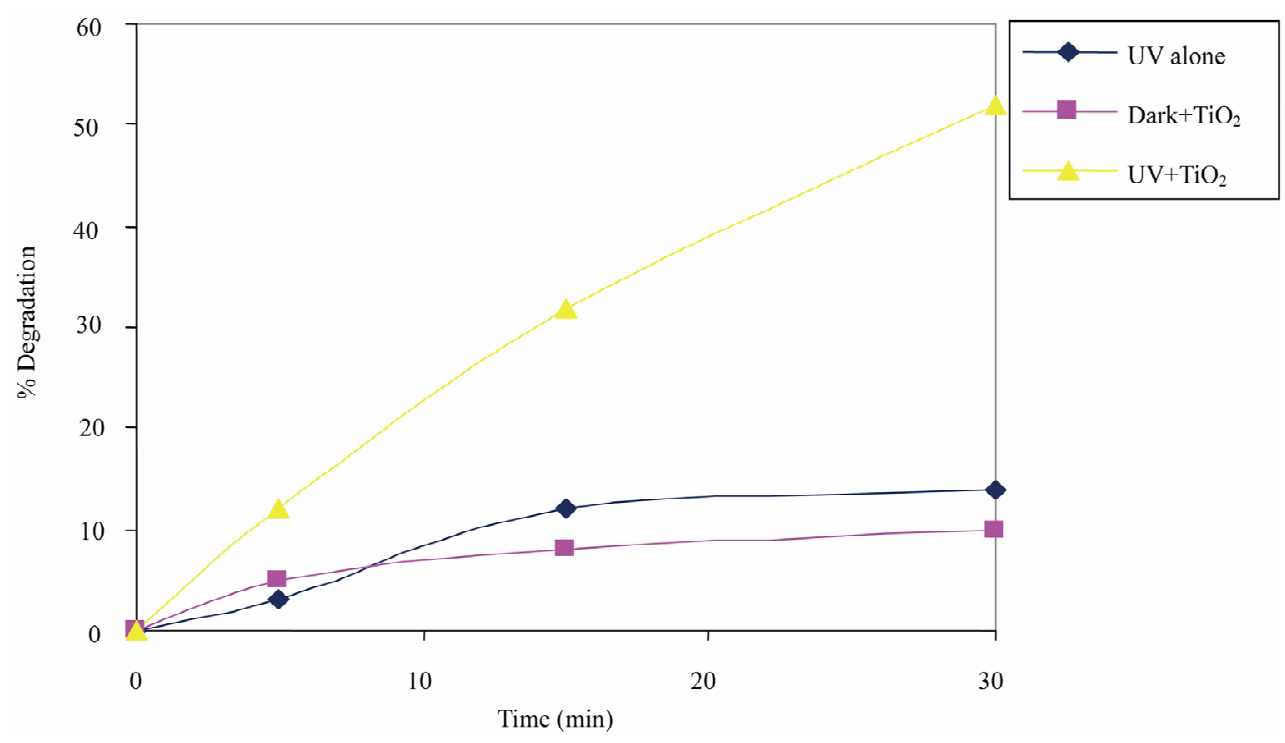

Figure 1. Photolysis/photocatalytic degradation of 2,6-DCP at natural pH. 
$0.25-1.5 \mathrm{~g} / \mathrm{L}, \mathrm{pH}(3-11)$ and initial substrate concentration $(5-100 \mathrm{mg} / \mathrm{L})$.

\subsubsection{Effect of Catalyst Dose}

The experiments were performed by varying catalyst dose from $0.25 \mathrm{~g} / \mathrm{L}$ to $1.5 \mathrm{~g} / \mathrm{L}$ for substrate solutions of $25 \mathrm{mg} / \mathrm{L}$ at natural $\mathrm{pH}$ to determine the effect of catalyst loading on the degradation. The results are shown in Figure 2. Maximum degradation was seen with $1.25 \mathrm{~g} / \mathrm{L}$ catalyst dose. Similar findings have been reported for the degradation of other pollutants [19]. The reason can be explained on the basis that optimum catalyst loading is found to be dependent on initial solute concentration because with the increase of catalyst dosage, total active surface area increases, hence availability of more active sites on catalyst surface [20].

Therefore further studies were carried out using 1.25 $\mathrm{g} / \mathrm{L}$ catalyst dose.

\subsubsection{Effect of $\mathbf{p H}$}

As wastewater containing organic pollutants like chlorophenols and dyes is discharged at different $\mathrm{pH}$; therefore it is very important to study the role of $\mathrm{pH}$ on degradation. To study the effect of $\mathrm{pH}$ on the degradation, experiments were carried out at various $\mathrm{pH}$ values, ranging from 3 - 11 for constant 2,6-DCP concentration $(25 \mathrm{mg} / \mathrm{L})$ and catalyst loading $(1.25 \mathrm{~g} / \mathrm{L})$. Figure 3 depicts the percentage degradation as a function of $\mathrm{pH}$. It can be observed that the maximum rate of degradation was achieved at $\mathrm{pH}$ 4. The literature [21-23] suggests that $\mathrm{TiO}_{2}$ surface

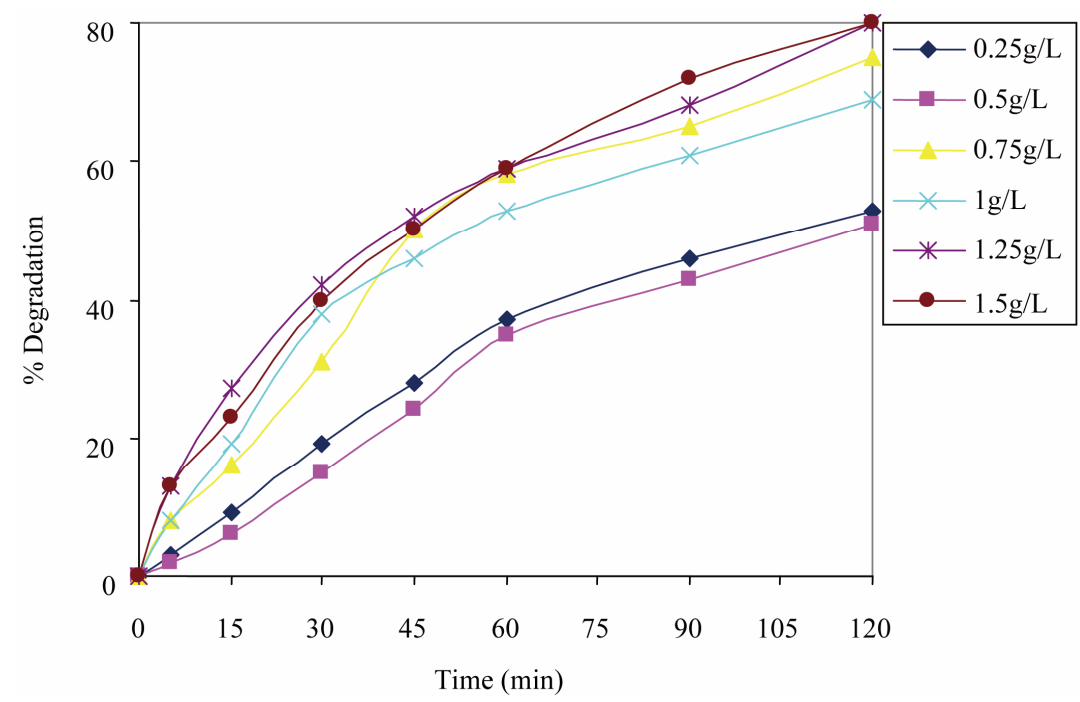

Figure 2. Effect of catalyst $\left(\mathrm{TiO}_{2}\right)$ dose on the photocatalytic degradation of 2,6-DCP.

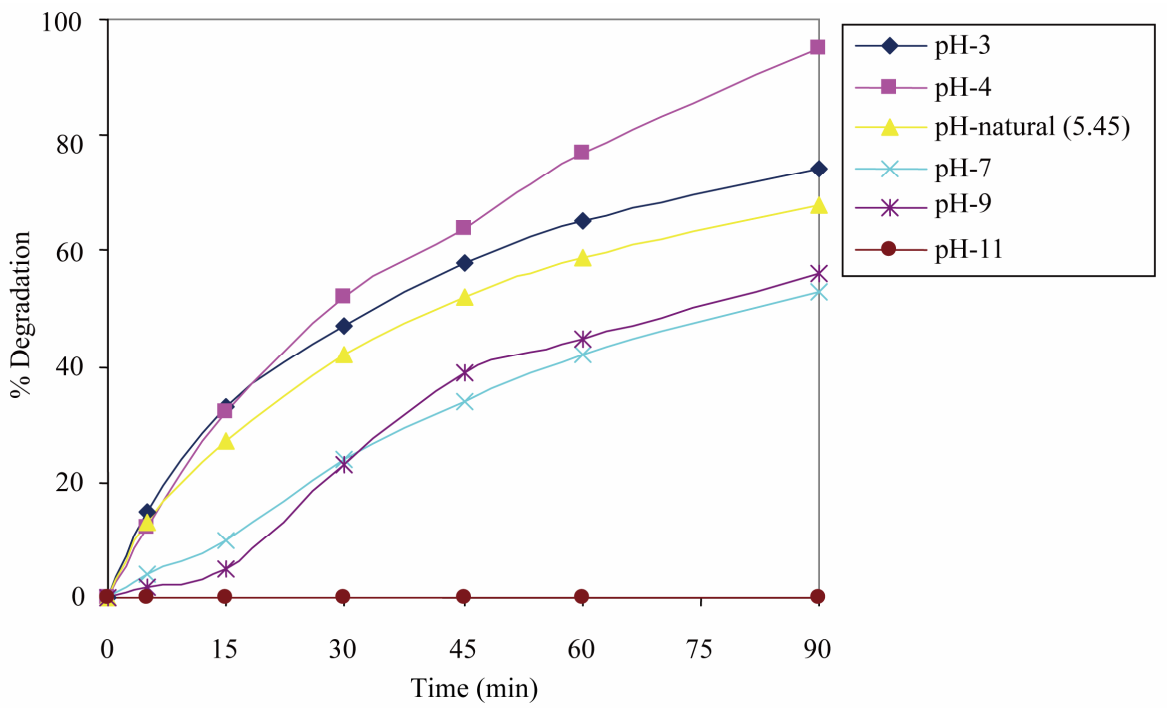

Figure 3. Effect of pH on photocatalytic degradation of 2,6-DCP. 
carries the net positive charge at low $\mathrm{pH}$ value (zpc for $\mathrm{TiO}_{2} \sim 6$ ), while the chlorophenols are primarily negatively and neutrally charged. Therefore, low $\mathrm{pH}$ values acilitates the adsorption of chlorophenols promoting their better photocatalytic degradation

\subsubsection{Effect of Initial Concentration of 2,6-DCP}

After optimizing the catalyst dose and $\mathrm{pH}$ conditions (catalyst dose $1.25 \mathrm{~g} / \mathrm{L}$ and $\mathrm{pH}-4$ ), the photocatalytic degradation of 2,6-DCP was carried out by varying the initial concentrations of 2,6-DCP from $5-100 \mathrm{mg} / \mathrm{L}$ in order to assess the appropriate amount of catalyst dose. As the initial concentration of the compound was increased, the rate of photodegradation decreased indicating for either to increase the catalyst dose or time span for the complete removal. Figure 4 shows the time dependent graphs of degradation of 2,6-DCP at different concentrations (5 - $100 \mathrm{mg} / \mathrm{L}$ ). For solutions of $25 \mathrm{mg} / \mathrm{L}$, almost $100 \%$ degradation was achieved within 90 minutes. For $50 \mathrm{mg} / \mathrm{L}$ of the 2,6-DCP solution, degradation was $54 \%$ in 90 minutes and it get further decreased on increasing the concentration of the substrate. It can be explained on the basis that as the initial concentration increases, more and more organic substances are adsorbed on the surface of $\mathrm{TiO}_{2}$ but the intensity of light and illumination time are constant.

\subsubsection{Kinetic Study}

The kinetic analysis of disappearance of 2,6-DCP for an initial concentration of $25 \mathrm{mg} / \mathrm{L}$ under optimized conditions is shown in Figure 5. The results indicate that the photocatalytic degradation in aqueous $\mathrm{TiO}_{2}$ can be

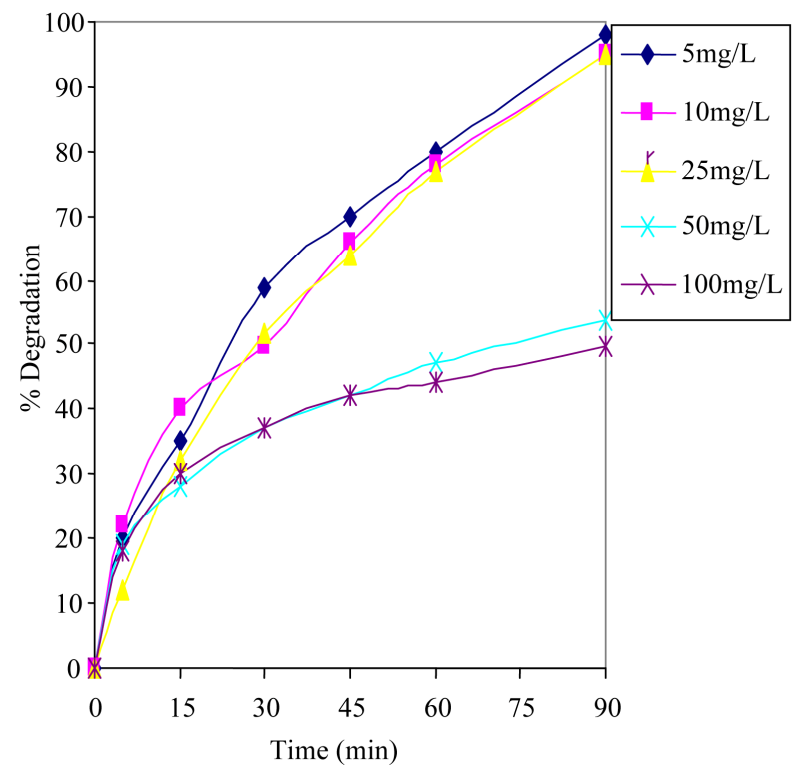

Figure 4. Effect of initial concentration of 2,6-DCP on degradation rate.

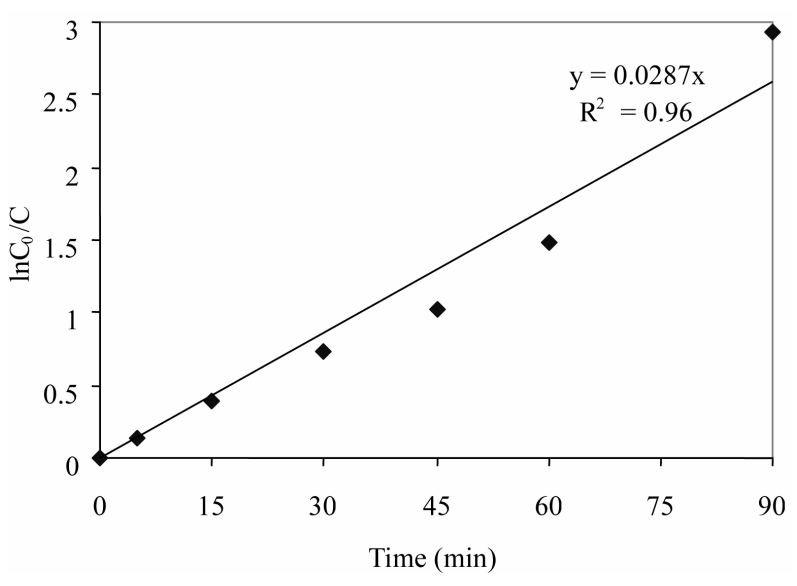

Figure 5. Kinetic analysis for 2,6-DCP.

described by the first order kinetic model, $\ln \left(\mathrm{C}_{0} / \mathrm{C}\right)=\mathrm{kt}$, where $\mathrm{C}_{0}$ is the initial concentration and $\mathrm{C}$ is the concentration at any time, $t$. The semi logarithmic plots of the concentration data gave a straight line. The correlation constant for the fitted line was calculated to be $\mathrm{R}^{2}=0.96$. The rate constant was estimated to be $4.78 \times 10^{-4} \cdot \mathrm{s}^{-1}$.

\section{Conclusion}

The chloro substituted phenol (2,6-DCP) was successfully degraded using $\mathrm{TiO}_{2}$ based photocatalysis process under UV light. The disappearance reaction followed pseudo-first order kinetics. The initial rate of photodegradation increased with increase in catalyst dose upto an optimum loading. Further increase in catalyst dose showed no effect. Maximum photodegradation efficiency was obtained in acidic range with $1.25 \mathrm{~g} / \mathrm{L} \mathrm{TiO}_{2}$ dose. As the initial concentration of the substrate was increased, the rate of degradation decreased.

\section{Acknowledgements}

The kind support obtained from Millennium Inorganic Chemicals, UK for providing samples of photocatalyst is sincerely acknowledged.

\section{REFERENCES}

[1] EPA, 2002. http://www.scorecard.org

[2] K. Hayward, "Drinking Water Contaminant Hit-List for US EPA,” Water 21, September-October 1998.

[3] L. H. Keith and W. A. Telliard, "Priority Polluants-A Perspective View," Environmental Science \& Technology, Vol. 13, No. 4, 1979, pp. 416-423.

[4] The European Parliament and of the Council, "EC Decision 2455/2001/EC of the European Parliament and of the Council of 20 November 2001: Establishing the List of Priority Substances in the Field of Water Policy and Amending Directive 2000/60/EC," The European Parliament and of the Council, 2001. 
[5] K. Abe and K. Tanaka, "Fe ${ }^{3+}$ and UV-Enhanced Ozonation of Chlorophenolic Compounds in Aqueous Medium," Chemosphere, Vol. 35, No. 12, 1997, pp. 2837-2847. doi:10.1016/S0045-6535(97)00344-5

[6] S. K. Kansal, M. Singh and D. Sud, "Optimization of Photocatalytic Process Parameters for the Degradation of 2,4,6-Trichlorophenol in Aqueous Solutions," Chemical Engineering Communications, Vol. 194, No. 6, 2007, pp. 787-802. doi:10.1080/00986440701193803

[7] T. Pandiyan, O. M. Rivas, J. O. Martinez, G. B. Amezcua and M. A. M. Carrillo, "Comparison of Methods for the Photochemical Degradation of Chlorophenols," Journal of Photochemistry and Photobiology A: Chemistry, Vol. 146, No. 3, 2002, pp. 149-155. doi:10.1016/S1010-6030(01)00606-2

[8] C. Sharma, S. Mohanty, S. Kumar and N. J. Rao, "Gas Chromatographic Analysis of Chlorophenolic, Resin and Fatty Acids in Effluents from Bleaching Processes of Agricultural Residues," International Journal of Environmental Analytical Chemistry, Vol. 64, No. 4, 1996, pp. 289-300. doi:10.1080/03067319608028350

[9] S. K. Kansal, M. Singh and D. Sud, "Parametric Optimization of Photocatalytic Degradation of Catechol in Aqueous Solutions by Response Surface Methodology," Indian Journal of Chemical Technology, Vol. 14, No. 2, 2007, pp. 145-153.

[10] H. K. Veschueren, "Handbook of Environmental Data on Organic Chemicals," VNR, New York, 1983.

[11] J. Folke and J. Birklund, "Danish Coastal Water Levels of 2,3,4,6-Tetrachlorophenol, Pentachlorophenol, and Total Organohalogens in Blue Mussels (Mytilus edulis)," Chemosphere, Vol. 15, No. 7, 1986, pp. 895-900. doi:10.1016/0045-6535(86)90054-8

[12] S. Mishra, V. Meda, A. K. Dalai, D. W. McMartin, J. V. Headley and K. M. Peru, "Photocatalysis of Naphthenic Acids in Water," Journal of Water Resource and Protection, Vol. 2, No. 7, 2010, pp. 644-650. doi:10.4236/jwarp.2010.27074

[13] S. K. Kansal, G. Kaur and S. Singh, "Studies on Photocatalytic Degradation of 2,3-Dichlorophenol Using Different Oxidants in Aqueous Solutions," Reaction Kinetics and Catalysis Letters, Vol. 98, No. 1, 2009, pp. 177-186. doi:10.1007/s11144-009-0058-5.

[14] Y. Ku and C. B. Hsieh, "Photocatalytic Decomposition of 2,4-Dichlorophenol in Aqueous $\mathrm{TiO}_{2}$ Suspensions," Water Research, Vol. 26, No. 11, 1992, pp. 1451-1456.

\section{doi:10.1016/0043-1354(92)90064-B}

[15] J. Bandara, J. A. Mielczarski, A. Lopez and J. Kiwi, "Sensitized Degradation of Chlorophenols on Iron Oxides Induced by Visible Light: Comparison with Titanium Oxide," Appied Catalysis B: Environmental, Vol. 34, No. 4, 2001, pp. 321-333.

[16] S. Antonaraki, E. Androulaki, D. Dimotikali, A. Hiskia and E. Papaconstantinou, "Photolytic Degradation of All Chlorophenols with Polyoxometallates and $\mathrm{H}_{2} \mathrm{O}_{2}$," Journal of Photochemistry and Photobiology A: Chemistry, Vol. 148, No. 1-3, 2002, pp. 191-197. doi:10.1016/S1010-6030(02)00042-4

[17] P. Saritha, C. Aparna, V. Himabindu and Y. Anjaneyulu, "Comparison of Various Advanced Oxidation Processes for the Degradation of 4-Chloro-2-nitrophenol," Journal of Hazardous Materials, Vol. 149, No. 3, 2007, pp. 609614. doi:10.1016/j.jhazmat.2007.06.111

[18] S. K. Kansal, N. Kaur and S. Singh, "Photocatalytic Degradation of Two Commercial Reactive Dyes in Aqueous Phase Using Nanophotocatalysts," Nanoscale Research Letters, Vol. 4, No. 7, 2009, pp. 709-716. doi:10.1007/s11671-009-9300-3

[19] A. Akyol, H. C. Yatmaz and M. Bayramoglu, "Photocatalytic Decolorization of Remazol Red RR in Aqueous ZnO Suspensions," Applied Catalysis B: Environmental, Vol. 54, No. 1, 2004, pp. 19-24. doi:10.1016/j.apcatb.2004.05.021

[20] M. S. T. Gonclaves, A. M. F. Oliveira-Campose, E. M. M. S. Pinto, P. M. S. Plasencia and M. J. R. P. Queiroz, "Photochemical Treatment of Solutions of Azo Dyes Containing $\mathrm{TiO}_{2}$," Chemosphere, Vol. 39, No. 5, 1999, pp. 781786.

[21] A. Mills, R. H. Davies and D. Worsley, "Water Purification by Semiconductor Photocatalysis," Chemical Society Reviews, Vol. 22, No. 6, 1993, pp. 417-425. doi:10.1039/cs9932200417

[22] A. Mills, S. Morris and R. Davies, "Photomineralisation of 4-Chlorophenol Sensitised by Titanium Dioxide: A Study of the Intermediates," Journal of Photochemistry and Photobiology A: Chemistry, Vol. 70, No. 2, 1993, pp. 183-191. doi:10.1016/1010-6030(93)85040-F

[23] U. Stafford, K. A. Gray and P. V. Kamat, "Radiolytic and $\mathrm{TiO}_{2}$-Assisted Photocatalytic Degradation of 4-Chlorophenol: A Comparative Study," Journal of Physical Chemistry, Vol. 98, No. 25, 1994, pp. 6343-6351. doi:10.1021/j100076a019 